\title{
Differentiation of human peripheral blood $V \delta 1+T$ cells expressing the natural cytotoxicity receptor NKp30 for recognition of lymphoid leukemia cells
}

Daniel V. Correia, Manuela Fogli, Kelly Hudspeth, Maria Gomes da Silva, Domenico Mavilio and Bruno Silva-Santos

Updated information and services can be found at:

http://bloodjournal.hematologylibrary.org/content/118/4/992.full.html

Articles on similar topics can be found in the following Blood collections Immunobiology (4524 articles)

Information about reproducing this article in parts or in its entirety may be found online at: http://bloodjournal.hematologylibrary.org/site/misc/rights.xhtml\#repub_requests

Information about ordering reprints may be found online at:

http://bloodjournal.hematologylibrary.org/site/misc/rights.xhtml\#reprints

Information about subscriptions and ASH membership may be found online at: http://bloodjournal.hematologylibrary.org/site/subscriptions/index.xhtml

Blood (print ISSN 0006-4971, online ISSN 1528-0020), is published weekly by the American Society of Hematology, 2021 L St, NW, Suite 900, Washington DC 20036.

Copyright 2011 by The American Society of Hematology; all rights reserved.

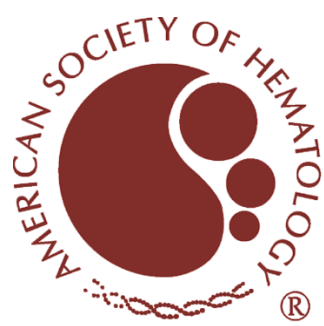




\title{
Differentiation of human peripheral blood $\mathrm{V} \delta 1^{+} \mathrm{T}$ cells expressing the natural cytotoxicity receptor NKp30 for recognition of lymphoid leukemia cells
}

\author{
Daniel V. Correia, ${ }^{1,2}$ Manuela Fogli, ${ }^{3}$ Kelly Hudspeth, ${ }^{3}$ Maria Gomes da Silva, ${ }^{4}$ Domenico Mavilio, ${ }^{3}$ and \\ *Bruno Silva-Santos ${ }^{1,2}$ \\ ${ }^{1}$ Instituto de Medicina Molecular, Faculdade de Medicina, Universidade de Lisboa, Lisboa, Portugal; ²Instituto Gulbenkian de Ciência, Oeiras, Portugal; \\ ${ }^{3}$ Laboratory of Clinical and Experimental Immunology, Istituto di Ricovero e Cura a Carattere Scientifico (IRCCS), Istituto Clinico Humanitas, Milan, Italy; and \\ ${ }^{4}$ Instituto Português de Oncologia de Lisboa, Francisco Gentil, Lisbon, Portugal
}

\begin{abstract}
The success of cancer immunotherapy depends on productive tumor cell recognition by killer lymphocytes. $\gamma \delta \mathrm{T}$ cells are a population of innate-like lymphocytes endowed with strong, MHCunrestricted cytotoxicity against tumor cells. This notwithstanding, we recently showed that a large proportion of human hematologic tumors is resistant to $\gamma \delta$ peripheral blood lymphocytes (PBLs) activated with specific agonists to the highly prevalent $\mathrm{V}_{\gamma} \mathbf{9} \mathrm{V} \delta 2 \mathrm{TCR}$. Although this probably constitutes an important limita-
\end{abstract}

tion to current $\gamma \delta \mathrm{T}$ cell-mediated immunotherapy strategies, we describe here the differentiation of a novel subset of V $\delta 2^{-}$V $\delta 1^{+}$PBLs expressing natural cytotoxicity receptors (NCRs) that directly mediate killing of leukemia cell lines and chronic lymphocytic leukemia patient neoplastic cells. We show that $\mathrm{V} \delta 1^{+} \mathrm{T}$ cells can be selectively induced to express NKp30, NKp44 and NKp46, through a process that requires functional phosphatidylinositol 3-kinase (PI-3K)/AKT signaling on stimulation with $\gamma_{c}$ cytokines and
TCR agonists. The stable expression of NCRs is associated with high levels of granzyme B and enhanced cytotoxicity against lymphoid leukemia cells. Specific gain-of-function and loss-of-function experiments demonstrated that NKp30 makes the most important contribution to TCR-independent leukemia cell recognition. Thus, $\mathrm{NKp} 30^{+} \mathrm{V} \delta 1^{+} \mathrm{T}$ cells constitute a novel, inducible and specialized killer lymphocyte population with high potential for immunotherapy of human cancer. (Blood. 2011;118(4):992-1001)

\section{Introduction}

Tumors develop in hosts endowed with a highly complex immune system that includes various lymphocyte subsets capable of recognizing and destroying transformed cells. It is now widely accepted that, although lymphocytes may constantly patrol tumor formation, cancer cells develop molecular strategies to evade immune surveillance, which are competitively selected under the pressure of the host immune system. ${ }^{1}$ This dynamic process, termed "cancer immunoediting," is thought to constitute a major obstacle to cancer immunotherapy. ${ }^{1}$

Among multiple immune evasion mechanisms, we have recently shown that leukemia and lymphoma primary cells often down-regulate the nonclassical MHC protein, ULBP1, which is critical for recognition of hematologic tumors by $\gamma \delta \mathrm{T}$ cells expressing the counter-receptor NKG2D. ${ }^{2} \gamma \delta$ T cells are innate-like lymphocytes that account for $1 \%-10 \%$ of peripheral blood lymphocytes (PBL) of healthy people and are capable of targeting a significant fraction of hematologic tumor cell lines tested in the laboratory. ${ }^{3}$ However, we have demonstrated that many lymphoid leukemia cells are resistant to fully activated $\mathrm{V} \gamma 9 \mathrm{~V} \delta 2 \mathrm{~T}$ cells, ${ }^{2,3}$ the dominant subset of $\gamma \delta$ PBLs. Furthermore, clinical trials involving the in vivo administration of activators of $\mathrm{V} \gamma 9 \mathrm{~V} \delta 2 \mathrm{~T}$ cells have shown limited success, with objective responses restricted to $10 \%-33 \%$ of patients with either hematologic or solid tumors. ${ }^{4-6}$ Even more modest has been the outcome of trials involving the adoptive transfer of activated and expanded $\mathrm{V} \delta 2^{+}$cells, because no objective responses have been reported. ${ }^{6}$ In fact, the simple ex vivo expansion of autologous $\mathrm{V} \delta 2^{+} \mathrm{T}$ cells, whose surveillance the tumor managed to escape in vivo, may be condemned to little therapeutic effect on reinjection into the patient. Therefore, we believe it is critical to invest in strategies that endow $\gamma \delta \mathrm{T}$ cells with additional recognition machinery to detect tumors that have resisted the natural components present in vivo.

Besides $\mathrm{V} \gamma 9 \mathrm{~V} \delta 2 \mathrm{~T}$ cells, $\mathrm{V} \delta 1^{+} \mathrm{T}$ cells are also endowed with potent antitumor cytolytic function, particularly as tissueassociated or tumor-infiltrating lymphocytes. ${ }^{7-10}$ Moreover, $\mathrm{V} \delta 1^{+}$ T cells can constitute up to $30 \%$ of all $\gamma \delta$ PBLs and may thus represent an important alternative population for adoptive cell therapy. However, this possibility remains poorly explored.

In this study we identified and characterized a novel $\mathrm{V} \delta 1^{+} \mathrm{PBL}$ subset capable of targeting hematologic tumors highly resistant to fully activated $\mathrm{V} \gamma 9 \mathrm{~V} \delta 2 \mathrm{PBLs}$. We show that this $\mathrm{V} \delta 1^{+}$population owes its specialized killer function to induced expression of natural cytotoxicity receptors (NCRs), which have been mostly regarded as NK-specific markers. Instead, we show that, although neither $\mathrm{V} \delta 1^{+}$ nor $\mathrm{V} \delta 2^{+}$cells express NCRs constitutively, these can be selectively up-regulated in ${\mathrm{V} \delta 1^{+}}^{+}$cells by AKT-dependent signals provided synergistically by $\gamma_{c}$ cytokines (IL-2 or IL-15) and TCR stimulation. We further show that NKp30 and NKp44 are both functional in $\mathrm{NCR}^{+} \mathrm{V} \delta 1^{+}$PBLs, and synergistically contribute to enhanced targeting of lymphocytic leukemia cells, with NKp30 playing the major role in this process. Thus, $\mathrm{NKp} 30^{+} \mathrm{V} \delta 1^{+} \mathrm{PBL}$
Submitted February 23, 2011; accepted May 15, 2011. Prepublished online as Blood First Edition paper, June 1, 2011; DOI 10.1182/blood-2011-02-339135.

${ }^{\star}$ D.M. and B.S.-S. contributed equally to this study.

The online version of this article contains a data supplement.
The publication costs of this article were defrayed in part by page charge payment. Therefore, and solely to indicate this fact, this article is hereby marked "advertisement" in accordance with 18 USC section 1734.

(C) 2011 by The American Society of Hematology 
constitute a novel promising population for adoptive cell immunotherapy of hematologic malignancies.

\section{Methods}

\section{Ethics statement}

Research involving clinical samples was conducted according to the principles expressed in the Helsinki Declaration. All procedures were approved by the review board of Instituto Português de Oncologia de Lisboa (Portugal).

\section{Isolation of human peripheral blood $\gamma \delta \mathrm{T}$ cells}

Peripheral blood was collected from anonymous healthy volunteers, diluted in a 1:1 ratio (volume-to-volume) with PBS (Invitrogen Gibco), and centrifuged in Ficol-Paque (Histopaque-1077; Sigma-Aldrich) in a volume ratio of 1:3 (1 part ficol to 3 parts diluted blood) for 30 minutes at $1500 \mathrm{rpm}$ and $25^{\circ} \mathrm{C}$. The interfase containing mononuclear cells was collected and washed (in PBS), and $\gamma \delta \mathrm{T}$ cells were isolated (to above $95 \%$ purity) by magnetic cell sorting via positive selection (with a FITC-labeled antiTCR $\gamma \delta$ antibody) or via negative selection (with a cocktail of Biotinlabeled antibodies; Miltenyi Biotec). When noted, $\mathrm{V} \delta 1^{+}$cells were further purified by magnetic cell sorting via positive selection with a FITC-labeled anti-V81 TCR antibody (Fisher Scientific) and anti-FITC microbeads (Miltenyi Biotec).

\section{Cell culture}

Isolated $\gamma \delta$ PBLs were cultured at $10^{6}$ cells $/ \mathrm{mL}$ at $37^{\circ} \mathrm{C}, 5 \% \mathrm{CO}^{2}$ in round-bottom 96 well plates with RPMI 1640 and $2 \mathrm{mM}$ l-glutamine (Invitrogen Gibco) supplemented with 10\% FBS (Invitrogen Gibco), $1 \mathrm{mM}$ sodium pyruvate (Invitrogen Gibco), and $50 \mathrm{mg} / \mathrm{mL}$ of penicillin and streptomycin (Invitrogen Gibco). The cells were expanded in the presence of $100 \mathrm{U} / \mathrm{mL}$ of rhIL-2 (Roche Applied Science), with or without $10 \mathrm{nM}$ of HMB-PP (4-hydroxy-3-methyl-but-2-enyl pyrophosphate; Echelon Biosciences) and $1 \mu \mathrm{g} / \mathrm{mL}$ of phytohemagglutinin (PHA; Sigma-Aldrich). Cells were washed and the culture medium was replaced every 5-6 days. To study the induction of NKp30 expression, $\gamma \delta$ PBLs were cultured in the presence or absence of $100 \mathrm{U} / \mathrm{mL}$ of rhIL-2 (Roche Applied Science), $1 \mu \mathrm{g} / \mathrm{mL}$ of soluble anti-CD3 antibody (eBioscience; clone OKT3), and $20 \mathrm{ng} / \mathrm{mL}$ of rhIL-15 (Biolegend). For TCR blockade, freshly isolated $\gamma \delta$ PBL were CFSE-labeled and then incubated for 7 days with anti-TCR $\gamma \delta$ (Beckman Coulter; clone IMMU510) diluted 1:20 in complete medium supplemented with $1 \mu \mathrm{g} / \mathrm{mL}$ PHA and $100 \mathrm{U} / \mathrm{mL}$ rhIL-2. To study the effects of chemical inhibitors of signal transduction, the MEK inhibitor UO126 and the PI-3K inhibitor LY294002 (both from Calbiochem) were added at $10 \mathrm{mM}$ for a 2-hour incubation period and then maintained in culture with $100 \mathrm{U} / \mathrm{mL}$ rhIL-2 and $1 \mu \mathrm{g} / \mathrm{mL}$ PHA for 7 days.

\section{Flow cytometric cell sorting}

For sorting of $\gamma \delta$ PBL based on the expression of NKp30 and $\mathrm{V} \delta 1^{+} \mathrm{TCR}$, cells from PHA and IL-2-activated cultures were stained with anti-NKp30 (Biolegend; clone P30-15), anti-Vס1 (Thermo Fisher Scientific; clone TS8.2), and sorted on a FACSAria cell sorter (BD Biosciences).

\section{Leukemia patient samples}

B-cell chronic lymphocytic leukemia cells were obtained from the peripheral blood of patients at presentation, after informed consent and institutional review board approval (Instituto Português de Oncologia de Lisboa, Portugal). Samples were enriched by density centrifugation over FicolPaque and then washed twice in 10\% RPMI 1640.

\section{In vitro tumor-killing assays}

All tumor cell lines (details provided in supplemental Table 1, available on the Blood Web site; see the Supplemental Materials link at the top of the online article) were cultured in complete 10\% RPMI 1640, maintained at
$10^{5}$ up to $10^{6}$ cells $/ \mathrm{mL}$ by dilution and splitting in a 1:3 ratio every 3-4 days. For cytotoxicity assays, magnetically purified $\gamma \delta$ PBL were preactivated for 7-19 days in the presence of IL-2 $(100 \mathrm{U} / \mathrm{mL})$ and either $1 \mu \mathrm{g} / \mathrm{mL}$ PHA or 10 nM HMB-PP. For receptor blocking, $\gamma \delta$ PBLs were incubated for 2 hours with the blocking antibodies anti-NKp30 (clone F252), anti-NKp44 (clone KS38), anti-NKp46 (clone KL247), anti-TCR $\gamma \delta$ (Beckman Coulter, clones IMMU510 or B1.1), or anti-V81 TCR (Fisher Scientific, clones TCS1 or TS8.2). The blocking antibodies were maintained in the culture medium during the killing assays. Tumor cell lines or leukemia primary samples were stained with CellTrace Far Red DDAO-SE $(1 \mu \mathrm{M}$; Molecular Probes, Invitrogen) and each batch of $3 \times 10^{4}$ tumor cells was incubated with $1.5 \times 10^{5}$ to $3 \times 10^{5} \gamma \delta \mathrm{T}$ cells in RPMI for 3 hours at $37^{\circ} \mathrm{C}$ and $5 \% \mathrm{CO}^{2}$ on a round-bottom plate with 96 wells. Cells were then stained with annexin V-FITC (BD Biosciences) and analyzed by flow cytometry. For the redirected killing assays, PHA and IL-2-activated $\gamma \delta$ PBL were incubated for 4 hours with the NCR agonists anti-NKp30 (clone AZ20), anti-Nkp44 (clone Z231) or anti-NKp46 (clone Bab281) during a standard ${ }^{51} \mathrm{Cr}$ release assay.

\section{Flow cytometry analysis}

Cells were labeled with the following fluorescent monoclonal antibodies: anti-CD3-PerCP-Cy5.5 (eBioscience; clone OKT3); anti-TCR $\gamma \delta-F I T C$ (eBioscience; clone B1.1); anti-CD69-PE (BD Pharmingen; clone FN50); anti-NKG2D-PE/Cy7 (Biolegend; clone 1D11); anti-2B4-APC (Biolegend, clone C1.7); anti-DNAM-1-Alexa-Fluor647 (Biolegend; clone DX11); anti-NKp30-APC (Biolegend; clone P30-15); anti-V82 TCR-PE (Biolegend; clone B6); anti-NKp44-APC (Biolegend; clone P44-8); anti-NKp46AlexaFluor647 (Biolegend; clone 9E2); anti-V81 TCR-FITC (Thermo Fisher Scientific; clone TS8.2); anti-NKp30-PE (Biolegend; clone P30-15); anti-Mouse IgG1к-APC Isotype Ctrl (Biolegend; clone MOPC-21); antiMouse IgG1к-PE Isotype Ctrl (Biolegend, clone MOPC-21); anti-CD27$\mathrm{APC} / \mathrm{Cy} 7$ (Biolegend, clone O323); and anti-CD56-APC (Biolegend, clone HCD56). Cell proliferation was measured by following a standard CFSE staining protocol (CellTrace CFSE Cell Proliferation Kit, Invitrogen; final concentration $0.5 \mathrm{mM}$ ), while apoptosis was assessed by annexin V-FITC (BD Pharmingen) staining. Cells were analyzed on a FACSCanto flow cytometer (BD Biosciences).

\section{RNA isolation and cDNA production}

Total RNA was extracted using the RNeasy Mini Kit according to the manufacturer's protocol (QIAGEN). Concentration and purity was determined by spectrophotometry and integrity was confirmed using an Agilent 2100 Bioanalyzer with a RNA 6000 Nano Assay (Agilent Technologies). Total RNA was reverse-transcribed into cDNA using random hexamers and Superscript II first strand synthesis reagents (Invitrogen).

\section{Real-time quantitative PCR}

Real-time quantitative PCR (qPCR) was performed on ABI Prism 7500 FAST Sequence Detection System using SYBR Green detection system (both from Applied Biosystems). Primers were designed using Primer3 v.0.4.0 online program (http://primer3.sourceforge.net). For each transcript, quantification was done using the calibration curve method. $\beta_{2}$-microglobulin $(B 2 M)$, Glucoronidase $\beta($ GUSB) and proteasome subunit $\beta$ type 6 (PSMB6) were used as housekeeping controls for normalization of gene expression. The following primers were used: $B 2 M$, forward CTAT CCAG CGTA CTCC AAAG ATTC, reverse CTTG CTGA AAGA CAAG TCTG AATG; $P S M B 6$, forward GGCG GCTA CCTT ACTA GCTG, reverse AAAC TGCA CGGC CATG ATA; GUSB, forward TGCA GCGG TGTA CTTC TG, reverse CCTT GACA GAGA TCTG GTAA TCA; B7H6, forward TCAC CAAG AGGC ATTC CGAC CT, reverse ACCA CCTC ACAT CGGT ACTC TC; NKP44, forward CCGT CAGA TTCT ATCT GGTG GT, reverse CACA CAGC TCTG GGTC TGG; NKP46, forward AAGA CCCC ACCT TTCC TGA, reverse TGCT GGCT CGCT CTCT AGT; GZMB, forward GGGG GACC CAGA GATT AAAA, reverse CCAT TGTT TCGT CCAT AGGA G. All samples were run in triplicate and repeated 3 times. Analysis of the qPCR results was performed using the ABI SDS v1.1 sequence analysis software (Applied Biosystems). 

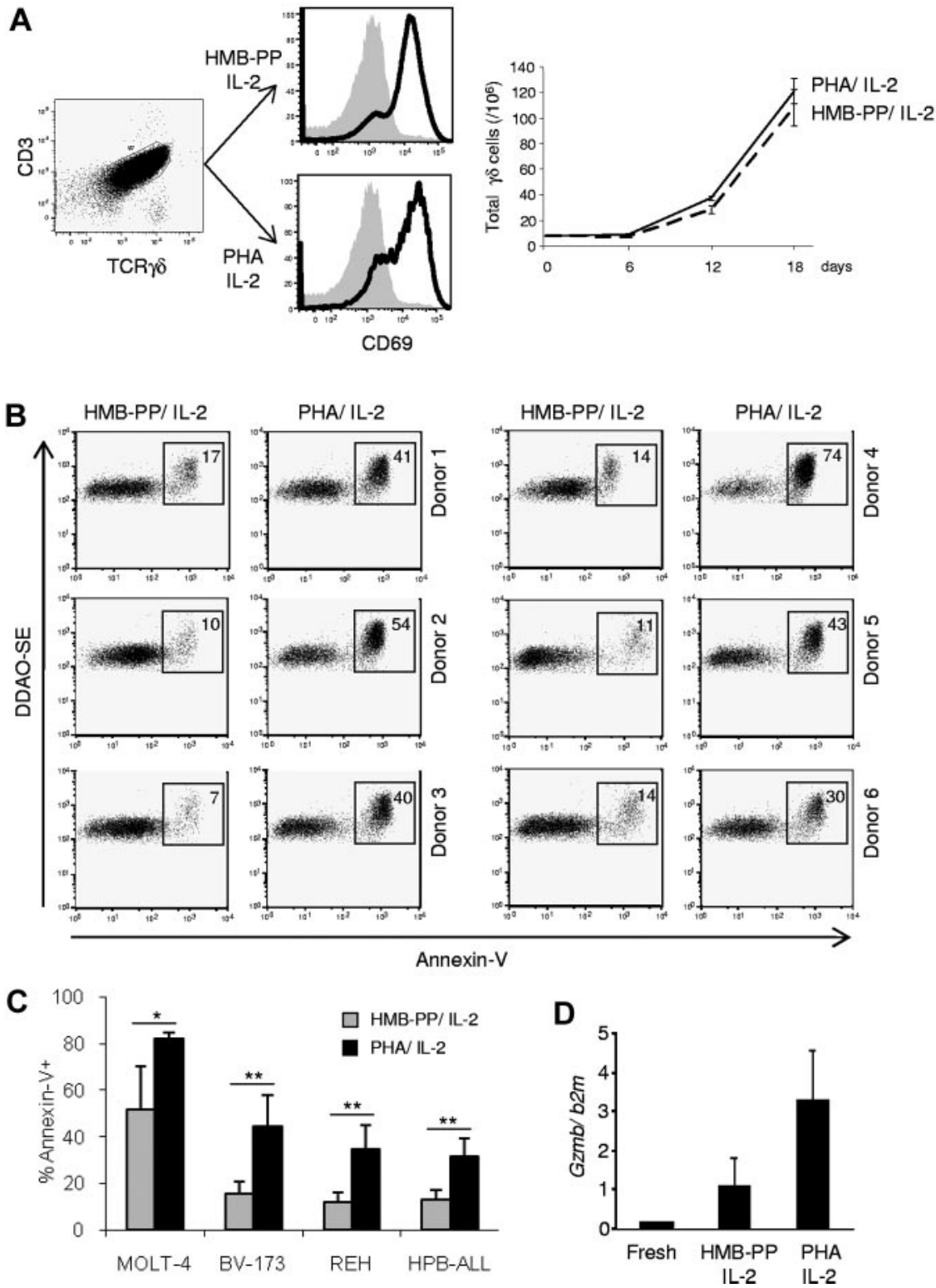

Figure 1. Enhanced antileukemia cytotoxicity of $\gamma \delta$ PBL cultures activated with pan-T-cell mitogen. (A) $\gamma \delta$ peripheral blood lymphocytes ( $\gamma \delta$ PBLs) were MACS-sorted from the peripheral blood of healthy volunteers (left panel), and stimulated with either HMB-PP and IL-2 or PHA and IL-2 for 4 to 19 days. Activation was evaluated by flow cytometry for CD69 up-regulation (middle panels; levels in freshly isolated control cells are shaded), and total cell numbers are shown on the right panel. (B-C) Preactivated (for 14 days, as in panel A) $\gamma \delta$ PBLs were coincubated with DDAOse-labeled leukemia cells for 3 hours. Tumor cell lysis was evaluated by annexin-V staining using flow cytometry. (B) Representative results of 6 different donors for the Bv173 leukemia cell line. Percentages refer to annexin-V+ tumor cells. Basal tumor cell apoptosis (in the absence of $\gamma \delta$ $\mathrm{PBL}$ ) was $<5 \%$. (C) Summary of the results of 6 different donors with 4 leukemia target cell lines. Error bars represent $\mathrm{SD}\left(\mathrm{n}=6\right.$, ${ }^{\star} P<.05$; $\left.{ }^{* \star} P<.01\right)$. (D) Real-time $\mathrm{PCR}$ quantification of GzmB mRNA levels in freshly isolated, HMB-PP and IL-2-activated and PHA and IL-2-activated $\gamma \delta$ PBL. Data in this figure are representative of 2 to 3 independent experiments with similar results.

\section{Statistical analysis.}

Differences between subpopulations were assessed using the Student $t$ test and are indicated when significant as $* P<.05$; $* * P<.01$; and $* * * P<.001$ in the figures.

\section{Results}

\section{Enhanced cytotoxicity of $\gamma \delta$ PBL cultures activated with pan-T-cell mitogen}

We compared the antitumor killing capacity of $\gamma \delta$ PBL cultures (always maintained in the presence of IL-2) activated either with
PHA, a plant lectin that acts as a potent T-cell mitogen, ${ }^{11}$ or the specific Vy9V82 TCR agonist HMB-PP. ${ }^{12,13}$ Although both regimens were similarly efficient at activating $\gamma \delta$ PBLs, as evaluated by CD69 up-regulation and cell proliferation (Figure 1A), we noted that samples activated with PHA were consistently better killers of hematopoietic tumor cell lines than samples (of the same donor origin) stimulated with HMB-PP (Figure 1B-C). This was valid across all donors tested (Figure 1B, supplemental Table 2, and data not shown) and was associated with higher expression of GZMB (Figure 1D), a key component of the lymphocyte cytolytic machinery. Of note, freshly isolated $\gamma \delta$ PBLs, which lack GZMB expression (Figure 1D), displayed very poor antileukemia cytotoxicity ( $<10 \%$ killing; not shown), as previously reported. ${ }^{13}$ 
Figure 2. Induction of natural cytotoxicity receptor expression in $\gamma \delta$ PBLs activated with pan-T-cell mitogen. $\gamma \delta$ PBLs were cultured as described in Figure 1 for 4-19 days and analyzed by flow cytometry for surface expression of various NK receptors. (A) Results for NKG2D, 2B4 and DNAM-1 in 10-day cultures activated either with HMB-PP and IL-2 (gray) or PHA and IL-2 (black), derived from 6 independent healthy donors. Error bars represent $\mathrm{SD}(\mathrm{n}=6 ; P>.05)$. (B) Expression of NKp30 in the same cultures of (A). FACS plots correspond to cultures derived from 3 individual donors. Percentages refer to $\mathrm{NKp} 0^{+} \gamma \delta \mathrm{PBLs}$. Isotype control staining is presented in supplemental Figure $2 \mathrm{~A}$. (C-D) Real-time PCR quantification of Nkp44 (C) and Nkp46 (D) mRNA levels in freshly isolated, HMB-PP and IL-2-activated and PHA and IL-2-activated $\gamma \delta$ PBL.

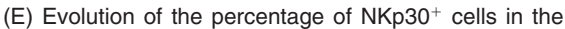
cultures described in (A), analyzed up to day 19. Error bars represent $S D(n=5)$. Data in this figure are representative of 2 to 4 independent experiments with similar results.
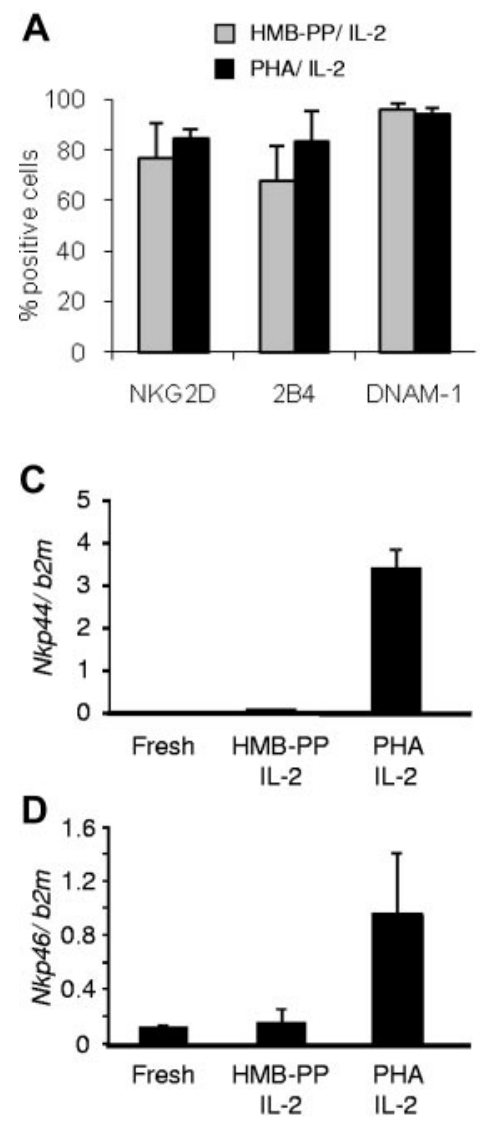

B

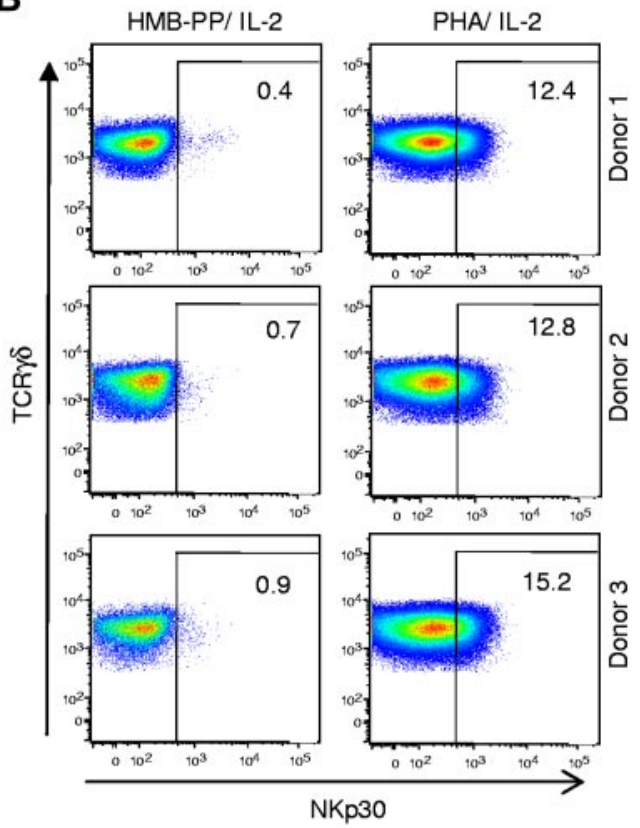

E

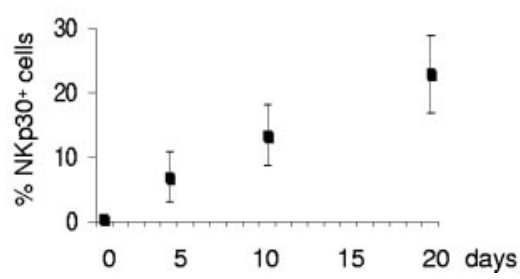

The superior cytotoxic function of PHA-stimulated $\gamma \delta$ PBL cultures was a surprising finding, because we and others have shown that HMB-PP is a very potent activator of the highly dominant V $\gamma 9$ V $\delta 2$ PBL subset. ${ }^{13}$ We were particularly interested that, compared with HMB-PP-activated $\gamma \delta$ PBL, PHA-stimulated cultures displayed improved cytotoxicity against various resistant leukemia cell lines, such as Bv-173, REH or HPB-ALL (Figure 1B-C), which we had shown to lack expression of the critical NKG2D ligand ULBP1. ${ }^{2,3}$ Of note, PHA-stimulated $\gamma \delta$ T cells did not target normal (healthy) PBMC (supplemental Figure 1). These data demonstrate that the pan-T-cell mitogen PHA is capable of increasing the cytolytic potential of medium-term (1-3 weeks) $\gamma \delta$ PBL cultures against leukemia cells, which could be of great value for adoptive cell immunotherapy.

\section{Induction of NCR expression on $\gamma \delta$ PBLs activated with pan-T-cell mitogen}

We next investigated the mechanism(s) underlying the enhanced cytotoxicity of PHA-activated $\gamma \delta$ PBL cultures. We considered that this could be explained by differential expression of receptors such as NKG2D, ${ }^{2,14,15}$ DNAM-1, ${ }^{16,17}$ or $2 \mathrm{~B} 4,{ }^{18}$ all previously shown to participate in tumor cell recognition by killer lymphocytes. However, none of these candidates was differentially expressed between PHA-activated and HMB-PP-activated $\gamma \delta$ PBL cultures (Figure 2A). By contrast, and unexpectedly, the natural cytotoxicity receptor NKp30, an important trigger of NK cell cytotoxicity, ${ }^{19}$ was specifically found on PHA-stimulated $\gamma \delta$ PBLs (Figure 2B; supplemental Figure 2A-B). Furthermore, the other NCR family members, NKp44 and NKp46, were also selectively expressed in these samples (Figure 2C-D; see next paragraph).
The proportion of $\mathrm{NKp} 30^{+}$cells increased steadily with culture time (Figure 2E), suggesting an association of NKp30 induction with cell proliferation. Although unlikely because of the very low background in fresh samples (Figure 2E), it was possible that a minute subset constitutively expressing NKp30 could be preferentially expanded in PHA-stimulated $\gamma \delta$ PBL cultures. However, experiments with highly (>99\%) FACS-purified NKp30-cells

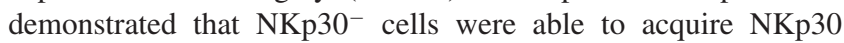
expression as efficiently as unsorted cells on PHA and IL-2 stimulation (supplemental Figure 3). Moreover, under such condi-

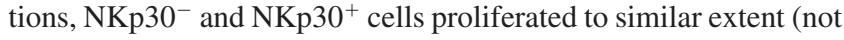
shown), further arguing against preferential expansion of $\mathrm{NKp}^{2} 0^{+}$ cells under such conditions. These results suggest that NKp30 expression is induced de novo on $\gamma \delta$ PBL activation by PHA and IL-2 treatment, which is coupled to cell proliferation.

\section{NCRs are selectively expressed by proliferating $\mathrm{V} \delta 1^{+} \mathrm{T}$ cells}

Considering that HMB-PP had been shown to be an optimal agonist of $\mathrm{V} \gamma 9 \mathrm{~V} \delta 2$ cells, ${ }^{12,13}$ we hypothesized that our findings derived from PHA-mediated activation of a distinct $\gamma \delta$ PBL subset. Consistent with this, we observed that, by contrast with HMB-PP, treatment with PHA preferentially expanded $\mathrm{V} \delta 2^{-}$cells among $\gamma \delta$ PBL (Figure 3A). We verified that this was not because of differences in $\mathrm{V} \delta 2^{+}$cell apoptosis in the 2 experimental conditions (supplemental Figure 2C). The most likely $\mathrm{V} \delta 2^{-}$population to expand so markedly (Figure $3 \mathrm{~A}$ ) were $\mathrm{V} \delta 1^{+}$cells, because other subsets are very rare in the peripheral blood of healthy adults. ${ }^{20}$ When V $\delta 1$ versus V $\delta 2$ TCR usage was assessed, a dramatic V $\delta 1^{+}$ cell enrichment was found in PHA-activated cultures $(>80 \%$ of all $\gamma \delta \mathrm{T}$ cells after 19 days; Figure 3B; supplemental Figure 4). 

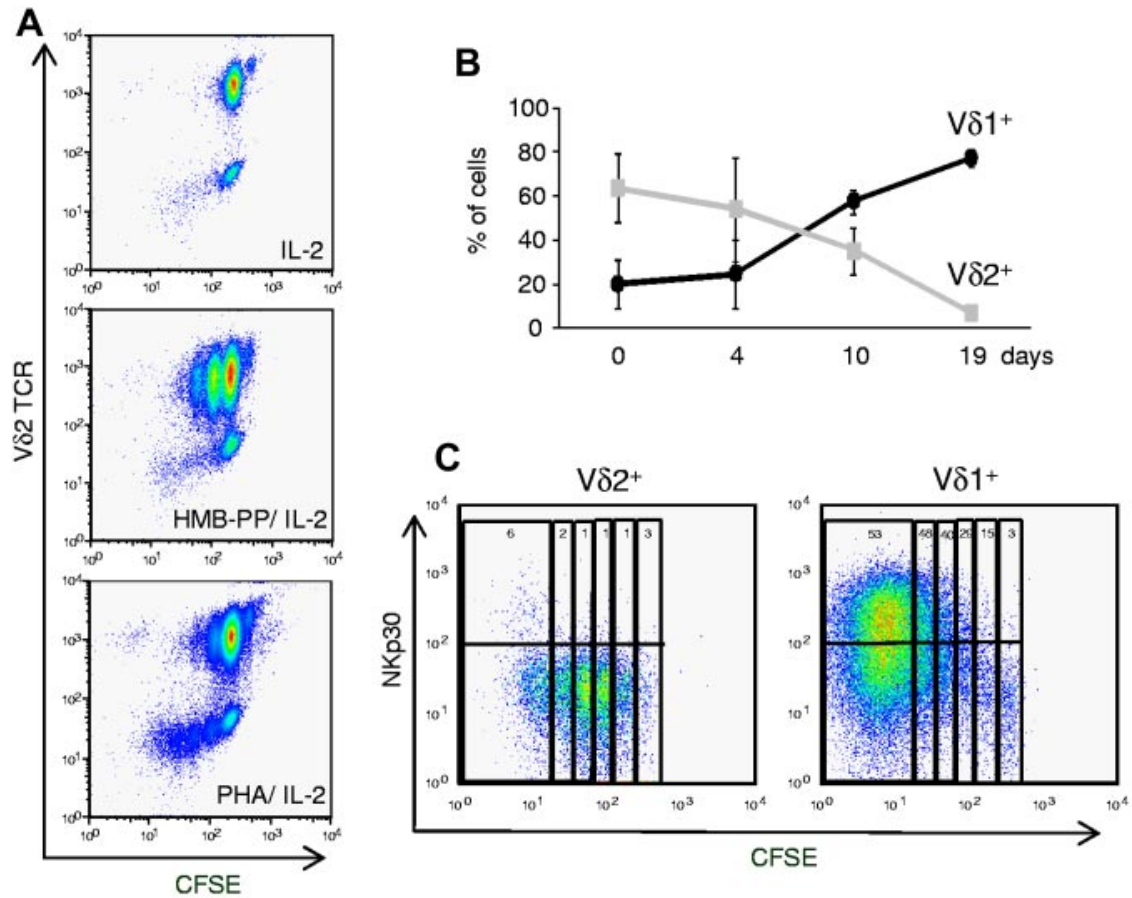

D
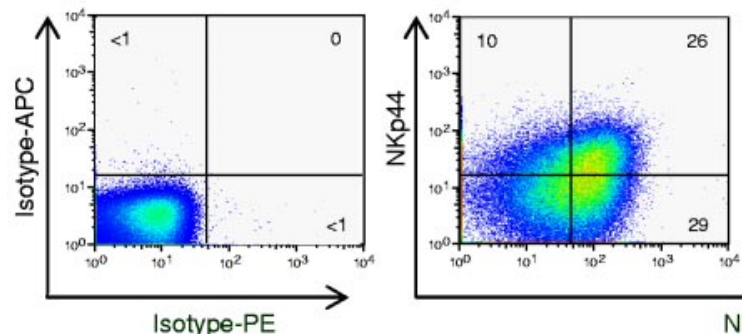

Figure 3. Natural cytotoxicity receptors are selectively expressed on proliferating $\mathbf{V} \delta 1^{+} \mathbf{T}$ cells. $(\mathrm{A}) \gamma \delta$ PBLs were labeled with CFSE and cultured as described in Figure 1, or in the absence of T cell mitogens (ie, IL-2 alone). Flow cytometry analysis of CFSE dilution and $\mathrm{V} \delta 2$ TCR expression after 7 days in culture. (B) Percentage of $\mathrm{V} \delta 1^{+}$or $\mathrm{V} \delta 2^{+}$cells among total $\gamma \delta$ PBLs cultured up to 19 days with PHA and IL-2. Error bars represent SD $(\mathrm{n}=3)$. (C) NKp30 expression in PHA and IL-2-activated $\gamma \delta$ PBL subsets. V $\delta 1^{+}$or $\mathrm{V} \delta 2^{+}$cells were FACS-sorted from peripheral blood, labeled with CFSE and cultured with PHA and IL-2 for 7 days. Percentages refer to

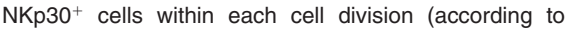
CFSE levels and indicated by vertical rectangles). (D) Expression of NKp30, NKp44 and NKp46 in V $81^{+} \mathrm{T}$ cells after 19 days of PHA and IL-2 stimulation. Isotype mAb control stainings are also shown. Data in this figure are representative of 2-3 independent experiments with similar results
Conversely, and as described, ${ }^{13} \mathrm{HMB}-\mathrm{PP}$-activated cultures were progressively dominated by $\mathrm{V} \delta 2^{+}$cells (Figure $3 \mathrm{~A}$; supplemental Figure 4).

The induction of NKp30 expression was examined in parallel cultures of isolated ${\mathrm{V} \delta 1^{+}}^{+}$or $\mathrm{V} \delta 2^{+}$cells, which were stimulated with PHA and IL-2. Although neither freshly isolated $\mathrm{V} \delta 1^{+}$nor V82 ${ }^{+}$cells expressed NKp30 (supplemental Figure 2B), this NCR was strongly induced (on PHA and IL-2 treatment) in $\mathrm{V} \delta 1^{+}$but not $\mathrm{V} \delta 2^{+}$cells (Figure 3C). Moreover, by following CFSE dilution, we demonstrated a striking accumulation of $\mathrm{NKp} 30^{+}$cells with progressive division of ${\mathrm{V} \delta 1^{+}}^{+}$cells (Figure 3C). These data suggest that activation of $\mathrm{V} \delta 1^{+}$cells in PHA and IL-2 cultures induces NKp30 expression concomitantly with cell proliferation.

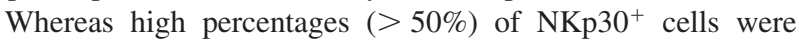
usually detected after 2 to 3 weeks in culture, NKp44 ( 30\%) and NKp46 $(<20 \%)$ were expressed in lower proportions of $\mathrm{V} \delta 1^{+}$

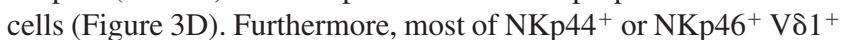
cells also expressed NKp30 (Figure 3D). We therefore considered NKp30 as the most informative marker of the inducible $\mathrm{NCR}^{+}$ $\mathrm{V} \delta 1^{+}$subset, and we set out to further characterize its differentiation.

\section{NKp30 induction requires AKT-dependent $\gamma_{c}$ cytokine and TCR signals}

We next dissected the specific signals required for the differentiation of $\mathrm{NCR}^{+} \mathrm{V} \delta 1^{+} \mathrm{T}$ cells. First, the 2 components of the activation protocol, IL-2 and PHA, were dissociated. IL-2, or its related $\gamma_{c}$ cytokine, IL-15, alone were sufficient to induce some NKp30 expression, but the effect was modest compared with PHA and IL-2 (or PHA and IL-15) combinations (Figure 4A and not shown). On the other hand, PHA alone was not able to keep the cultures viable (data not shown), consistent with the critical role of $\gamma_{c}$ cytokines in the survival of $\gamma \delta$ T cells, particularly on activation and proliferation. ${ }^{13,21}$

Although PHA has been a widely used T cell mitogen, it is also a nonphysiologic compound capable of cross-linking a series of surface receptors, including the TCR. ${ }^{22}$ We hypothesized that the molecular mediator of PHA stimulation could be the $\mathrm{V} \delta 1^{+} \mathrm{TCR}$ complex. We therefore compared the ability of PHA and the OKT3 $\mathrm{mAb}$, which specifically cross-links CD $3 \epsilon$ chains of the TCR complex, to induce NKp30 expression (when combined with IL-2 or IL-15) in $\mathrm{V} \delta 1^{+} \mathrm{T}$ cells. OKT3 was fully capable of mimicking PHA in these assays (Figure 4A-B), thus inducing NKp30 in proliferating $\mathrm{V} \delta 1^{+} \mathrm{T}$ cells (supplemental Figure 5). Moreover, TCR $\gamma \delta$ blockade in PHA and IL-2 cultures prevented NKp30 induction (Figure 4C). These data suggest that PHA treatment provides TCR signals to induce NCR expression on $\mathrm{V} \delta 1^{+} \mathrm{PBL}$. Moreover, the differences between cytokine alone or combination treatments with OKT3 (or PHA) highlight a marked synergy between $\gamma_{c}$ cytokine and TCR signals in this process (Figure 4A-B). 
A

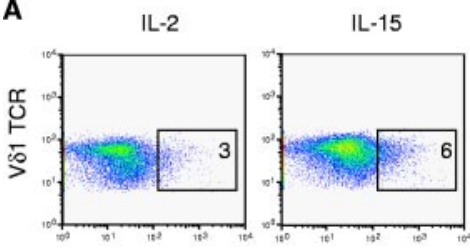

B

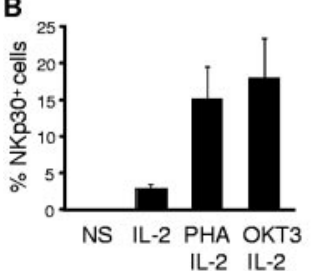

C

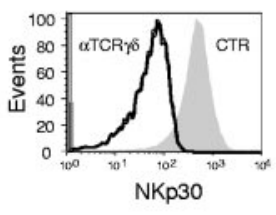

PHA/IL-2

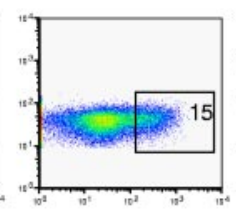

OKT3/ IL-2

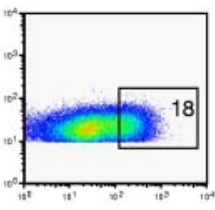

OKT3/ IL-15
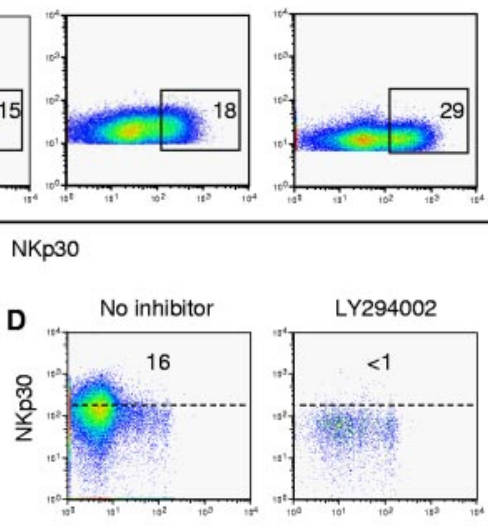

LY294002

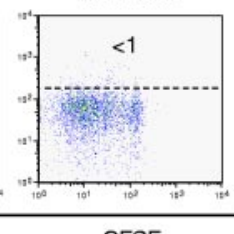

CFSE
OKT3/IL-2/ IL-15
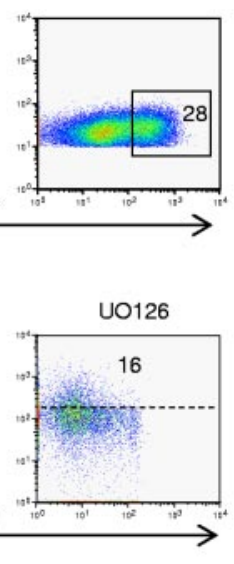

Figure 4. AKT-dependent $\gamma_{c}$ cytokine and TCR signals induce NKp30 expression in V $\delta 1^{+} \mathbf{T}$ cells. (A-B) Flow cytometry analysis of NKp30 expression on pregated $\mathrm{V} \delta 1^{+}$ T cells from $\gamma \delta$ PBL cultures after 7 days in the presence of IL-2 or IL-15, alone or in combination with PHA or OKT3 (anti-CD3 $\epsilon$ mAb). (C) Effect of blocking anti-TCR $\gamma \delta$ mAb on NKp30 induction in PHA and IL-2-activated $\gamma \delta$ PBLs. The shaded gray area is pregated NKp30+ cells in 7-day control cultures. (D) Effect of chemical inhibitors LY294002 and UO126 on NKp30 induction in PHA and IL-2-activated $\gamma \delta$ PBLs, prelabeled with CFSE. Data in this figure are representative of 2 to 3 independent experiments with similar results.

To further explore the molecular mechanisms of NCR induction, we used chemical inhibitors of key signal transduction pathways downstream of $\gamma_{c}$ cytokine receptors and/or TCR signaling. Although blocking JAK signaling triggered extensive cell death before any NCR induction (not shown), coincubation with the PI-3K/ AKT inhibitor LY294002 specifically prevented NKp30 induction in proliferating ${\mathrm{V} \delta 1^{+}}^{-} \mathrm{T}$ cells (Figure 4D). AKT is involved in transducing both $\gamma_{\mathrm{c}}$ cytokine and TCR signals, ${ }^{23}$ including TCR $\gamma \delta$ signals. ${ }^{13}$ By contrast, the MAPK/Erk inhibitor UO126 had no detectable effect on NKp30 induction in proliferating ${\mathrm{V} \delta 1^{+}}^{+} \mathrm{T}$ cells (Figure 4D). Importantly, the selective effect of LY294002 dissociated NCR induction from cell proliferation, thus demonstrating that $\mathrm{V} \delta 1^{+} \mathrm{T}$-cell proliferation is necessary (Figure 3C; supplemental Figure 5) but not sufficient (Figure 4D) to induce NKp30 expression. Collectively, these data demonstrate that AKTdependent $\gamma_{c}$ cytokine and TCR signals synergize to induce NKp30 expression in $\mathrm{V} \delta 1^{+} \mathrm{T}$ cells.

\section{Functional NKp30 and NKp44 trigger tumor cell killing by V $\delta 1^{+}$ PBLs}

Although the previous data established clear associations between NKp30 expression and increased cytotoxicity of $\gamma \delta\left(\mathrm{V} \delta 1^{+}\right) \mathrm{PBL}$ cultures, the functional role of NCRs in this system remained to be formally demonstrated. We therefore undertook gain-of function and loss-of-function experiments to evaluate the effect of NCR modulation on ${\mathrm{V} \delta 1^{+}}^{+}$enriched ( $>80 \%$; supplemental Figure 3A) PBL cultures, which expressed NCRs at levels similar to those in Figure 3D (not shown). First, using a reverse Ab-dependent cytotoxicity assay, we showed that cross-linking of NKp30 or NKp44, but not NKp46, produced significant increases in lysis of the P815 tumor cell targets (Figure 5A). These data demonstrate that induced NKp30 and NKp44 are functional and mediate tumor cell killing. To assess if they played nonredundant roles in targeting leukemia cells, we performed receptor blockade experiments using NCR-specific mAbs (kindly provided by Dr A. Moretta, University of Genova, Italy). We observed significant reductions in tumor cell lysis on NKp30 and NKp44 blockade (Figure 5B). As expected from the results in Figure 5A, NKp46 blockade did not affect tumor cell killing. Interestingly, a synergistic effect between NKp30 and NKp44 was also clearly observed. Of note, TCR $\gamma \delta$ blockade in any setting (alone or in combination with anti-NCR mAbs) was a neutral event during the killing assay (Figure 5B). To further establish the TCR-independence of $\mathrm{NCR}^{+} \mathrm{V} \delta 1^{+} \mathrm{PBL}$ cytotoxicity, we isolated PHA-activated $\mathrm{V} \delta 1^{+}$cells to very high purity (supplemental Figure 6) and used 3 different well-described anti-TCR blocking antibodies, including one (TCS1) specific for the $\mathrm{V} \delta 1^{+}$ TCR. Again, we observed no effect on leukemia cell killing (Figure 5C). By contrast, inhibition of NKG2D had a significant (Figure 5C) and dose-dependent (supplemental Figure 6C) impact on tumor lysis. In fact, when we combined NCR and NKG2D inhibition, $\mathrm{NCR}^{+} \mathrm{V} \delta 1^{+}$PBLs could not kill above background levels (Figure 5C). These data suggest that leukemia cell targeting by $\mathrm{NCR}^{+} \mathrm{V} \delta 1^{+}$PBLs is a TCR-independent event mostly mediated by the synergistic function of NKp30, NKp44 and NKG2D.

\section{$\mathrm{NKp} 0^{+} \mathrm{V} \delta 1^{+} \mathrm{PBL}$ are specialized killers that target resistant primary lymphocytic leukemias}

To fully characterize the antitumor potential of $\mathrm{NCR}^{+} \mathrm{V} \delta 1^{+} \mathrm{PBL}$,

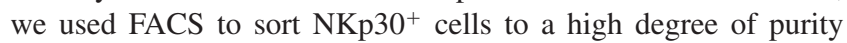
(>99\%; Figure 6A) and performed a series of functional assays.

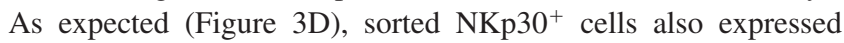
NKp44 and NKp46 (Figure 6B), and the 3 NCRs were largely stable on the surface of the purified cells when cultured for 2 weeks with IL-2 alone (Figure 6C). These data demonstrate the feasible expansion of a stable $\mathrm{NCR}^{+} \mathrm{V} \delta 1^{+} \mathrm{T}$ cell subset.

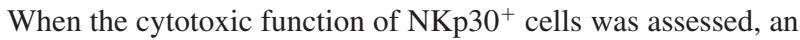
increased targeting of the resistant leukemia cell line Bv173 (among others; not shown) was observed (in comparison with

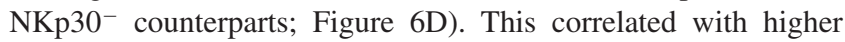
expression of granzyme B (Figure 6E). Moreover, NKp30 expression also associated with higher degree of CD56 expression (supplemental Figure 7), which has been previously linked to cytotoxicity of human lymphocytes, including V $\delta 2^{+} \mathrm{T}$ cells ${ }^{24}$ ).

Finally, we performed functional killing assays with primary samples obtained from B-cell chronic lymphocytic leukemia patients. We previously showed that such specimens are considerably resistant to $\gamma \delta$ PBL activated and expanded with the specific Vy9V82 TCR agonist HMB-PP, ${ }^{3}$ a finding confirmed in this study (Figure 6F-G). Importantly, HMB-PP and IL-2-activated $\gamma \delta$ PBLs do not express NCRs (Figure 2B). We therefore compared their antitumor cytolytic activity with that of $\mathrm{NKp} 30^{+}$cells isolated from $\gamma \delta$ PBL cultures activated with PHA and IL-2. We observed 


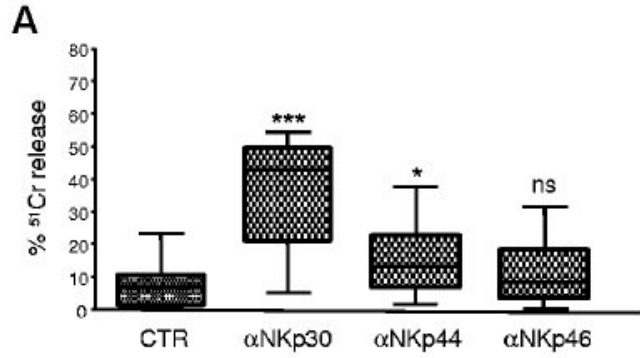

B
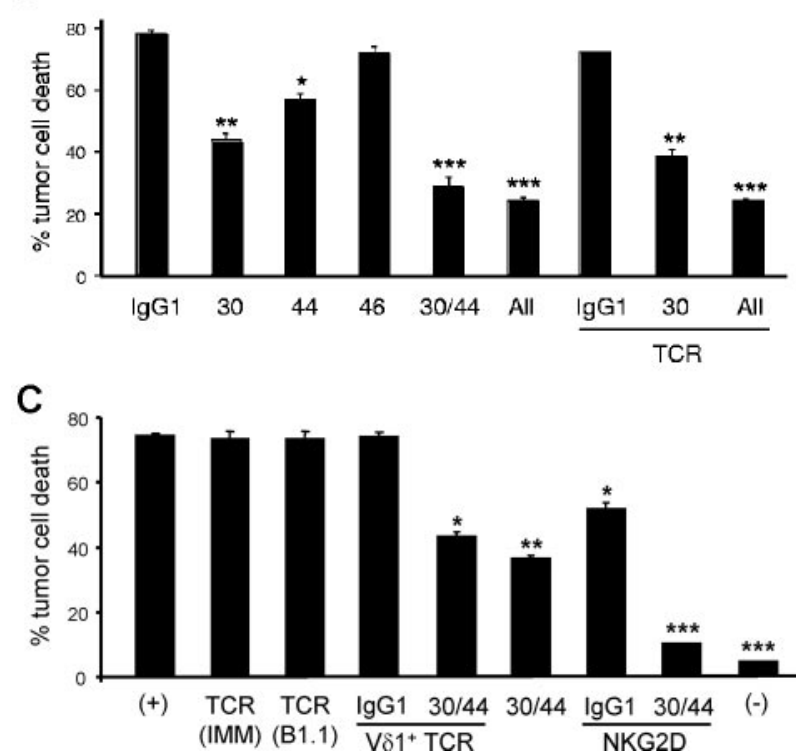

Figure 5. NKp30 and NKp44 mediate tumor cell killing by $\mathrm{NCR}^{+} \gamma \delta \mathrm{PBLs}^{+}$ (A) Functional evaluation of NKp30, NKp44 and NKp46 using specific monoclonal antibodies in a 4-hour ${ }^{51} \mathrm{Cr}$ release redirected killing assay (at 2:1 effector:target ratio) of the Fc $\gamma \mathrm{R}^{+} \mathrm{P} 815$ target cell line by $\gamma \delta$ PBLs activated and expanded with PHA and IL-2. Data are presented as mean and SD of 8 independent experiments performed in triplicate $\left({ }^{\star} P<.05,{ }^{\star \star *} P<.001 ; \mathrm{ns}=\right.$ not statistically significant). (B) $\gamma \delta$ PBLs activated and expanded for 18 days in PHA and IL-2 were incubated (at 5:1 effector:target ratio) for 3 hours with the leukemia cell line MOLT-4 (as in Figure 1). Effect of blocking antibodies to NKp30, NKp44, NKp46 and TCR $\gamma \delta$ (IMMU510) on tumor cell killing. (C) V $\delta 1+$ PBLs were MACS-sorted after 20 days in PHA and IL-2 cultures for the assay described in (B), but using blocking antibodies to pan-TCR $\gamma \delta$ (IMMU510 and B1.1), V81 + TCR (TCS1), NKG2D or NKp30 and NKp44, or the depicted combinations. $(+)$ refers to control cultures without inhibitory antibodies; (-) refers to tumor cell cultures without V81+ PBLs. Error bars represent $\mathrm{SD}\left(\mathrm{n}=3,{ }^{\star} P<.05 ;{ }^{* \star} P<.01\right.$; $\left.{ }^{\star * \star} P<.001\right)$.

that NKp30 ${ }^{+} \gamma \delta$ PBLs, obtained from 6 different donors, were consistently more efficient at eliminating primary B-CLL cells (Figure 6F-G). These data collectively suggest that highly cytotoxic $\mathrm{NKp} 30^{+} \mathrm{V} \delta 1^{+} \mathrm{PBL}$ are promising new candidates for adoptive cell immunotherapy of hematologic malignancies.

\section{Discussion}

Natural cytotoxicity receptors were identified by A. Moretta and colleagues over a decade ago, and were shown to play critical synergistic roles in the antitumor functions of NK cells. ${ }^{19,25-27}$ In fact, NKp30 and NKp46 are widely considered to be 2 of the most specific NK markers ${ }^{19,25-27}$ We now show that the combination of cytokine (IL-2 or IL-15) and mitogenic (PHA or OKT3) stimuli induces NCR expression in a sizeable $\mathrm{V} \delta 1^{+} \mathrm{PBL}$ subset that is endowed with increased cytolytic activity against hematologic tumors. Although PHA is a nonphysiologic T-cell mitogen, we demonstrated that its effect on NCR induction was fully mimicked by crosslinking the TCR-CD 3 complex on $\mathrm{V} \delta 1^{+}$PBL. Thus, NCR induction is coupled to TCR-mediated proliferation of $\mathrm{V} \delta 1^{+}$cells, while also requiring $\gamma_{c}$ cytokine signals. This is consistent with previous reports demonstrating that the in vitro acquisition of NK receptors by liver ${ }^{28}$ or umbilical cord ${ }^{29} \mathrm{~T}$ cells depends on IL-15.

Among inducible NCRs, NKp30 is clearly the most important for the antitumor activity of $\mathrm{V} \delta 1^{+} \mathrm{T}$ cells, based on the proportion of cells that express it (Figure 3D), the higher enhancement in $\mathrm{V} \delta 1^{+} \mathrm{T}$-cell cytotoxicity on NKp30 triggering (Figure 5A), and the significant reduction in leukemia cell killing on NKp30 blockade (Figure 5B). This notwithstanding, NKp44 (but not NKp46) is also functional in $\mathrm{NCR}^{+} \mathrm{V} \delta 1^{+}$cells (Figure 5A), and appears to synergize with NKp30 for enhanced tumor targeting (Figure 5B). Of note, NKp30 engagement also augments the production of the key antitumor cytokine, interferon- $\gamma$, by $\mathrm{NCR}^{+} \mathrm{V} \delta 1^{+}$cells (supplemental Figure 8).

Both NKp30 30 and NKp $44^{31}$ have been implicated in human NK cell recognition of virus-infected cells. Regarding tumors, antibody-mediated blocking experiments demonstrated important roles for these receptors in myeloma ${ }^{32}$ and melanoma ${ }^{33}$ cell targeting. Moreover, lack of NCR expression has been clinically correlated with poor survival in AML patients. ${ }^{34}$

Interestingly, NKp30 and NKp44 are not encoded in the genome of murine strains (such as $\mathrm{C} 57 \mathrm{Bl} / 6$ or Balb/c) widely used for laboratory experimentation. ${ }^{35}$ On the other hand, the major Vy9V82 subset of human PBL, and its reactivity toward phosphoantigens, are also primate-specific. ${ }^{6}$ These observations highlight the special functional characteristics of primate $\gamma \delta \mathrm{T}$ cells; however, they also preclude the direct in vivo study of $\mathrm{V} \gamma 9 \mathrm{~V} \delta 2$ or $\mathrm{NKp} 30^{+} \mathrm{V} \delta 1^{+} \mathrm{T}$ cells in the mouse.

Another aspect that currently limits our understanding of NCR function in immunity is the poor definition of their physiologic ligands, most notably in the context of tumors. In fact, viral hemagglutinin was until recently the only well-established ligand for NKp44 $4^{36}$ and NKp46. ${ }^{37}$ This notwithstanding, a novel B7 family member, B7-H6, was lately described to bind NKp30. ${ }^{38}$ B7-H6 was not detected in normal human tissues but was expressed on human tumor cells, ${ }^{38}$ in line with the recognition of "stressed self" by innate and innate-like lymphocytes. ${ }^{14,39}$ However, we obtained no evidence for a role of B7-H6 in $\mathrm{NCR}^{+} \mathrm{V} \delta 1^{+} \mathrm{T}$-cell recognition of lymphoid leukemias; in fact, many of the $\mathrm{NCR}^{+}$ $\mathrm{V} \delta 1^{+} \mathrm{T}$-cell targets expressed lower levels of B7-H6 than healthy control cells (supplemental Figure 9). Brandt et al had also previously noted that only 24 of 119 tumor cell lines tested expressed B7-H6. ${ }^{38}$ Thus, future lines of research should clarify the repertoire of relevant ligands expressed by tumors susceptible to NKp30-mediated cytotoxicity. Moreover, although we have thus far concentrated on hematologic malignancies, upcoming work will address whether $\mathrm{NKp} 30^{+} \mathrm{V} \delta 1^{+}$lymphocytes also possess enhanced cytotoxicity against solid tumors. Of note, $\mathrm{V} \delta 1^{+} \mathrm{T}$ cells have previously been shown to be cytolytic against melanoma and various carcinomas. ${ }^{10}$

$\mathrm{V} \delta 1^{+} \mathrm{T}$ cells are the predominant $\gamma \delta \mathrm{T}$-cell subset during the fetal stage and early life, ${ }^{40}$ when they are already able to respond to viral infection. ${ }^{41}$ In adults, $\mathrm{V} \delta 1^{+} \mathrm{T}$-cell expansions have been associated with CMV infection, ${ }^{42} \mathrm{HIV}-1$ infection, ${ }^{43}$ and tumors of either epithelial ${ }^{7-9}$ or hematopoietic ${ }^{44,45}$ origin. An attractive prospect for adoptive transfer of activated $\mathrm{V} \delta 1^{+} \mathrm{T}$ cells is that they may display particularly good capacity for homing to tissues because, contrary to their circulating $\mathrm{V} \delta 2^{+}$counterparts, $\mathrm{V} \delta 1^{+}$cells are preferentially tissue-associated lymphocytes. ${ }^{9}$ Interestingly, the 

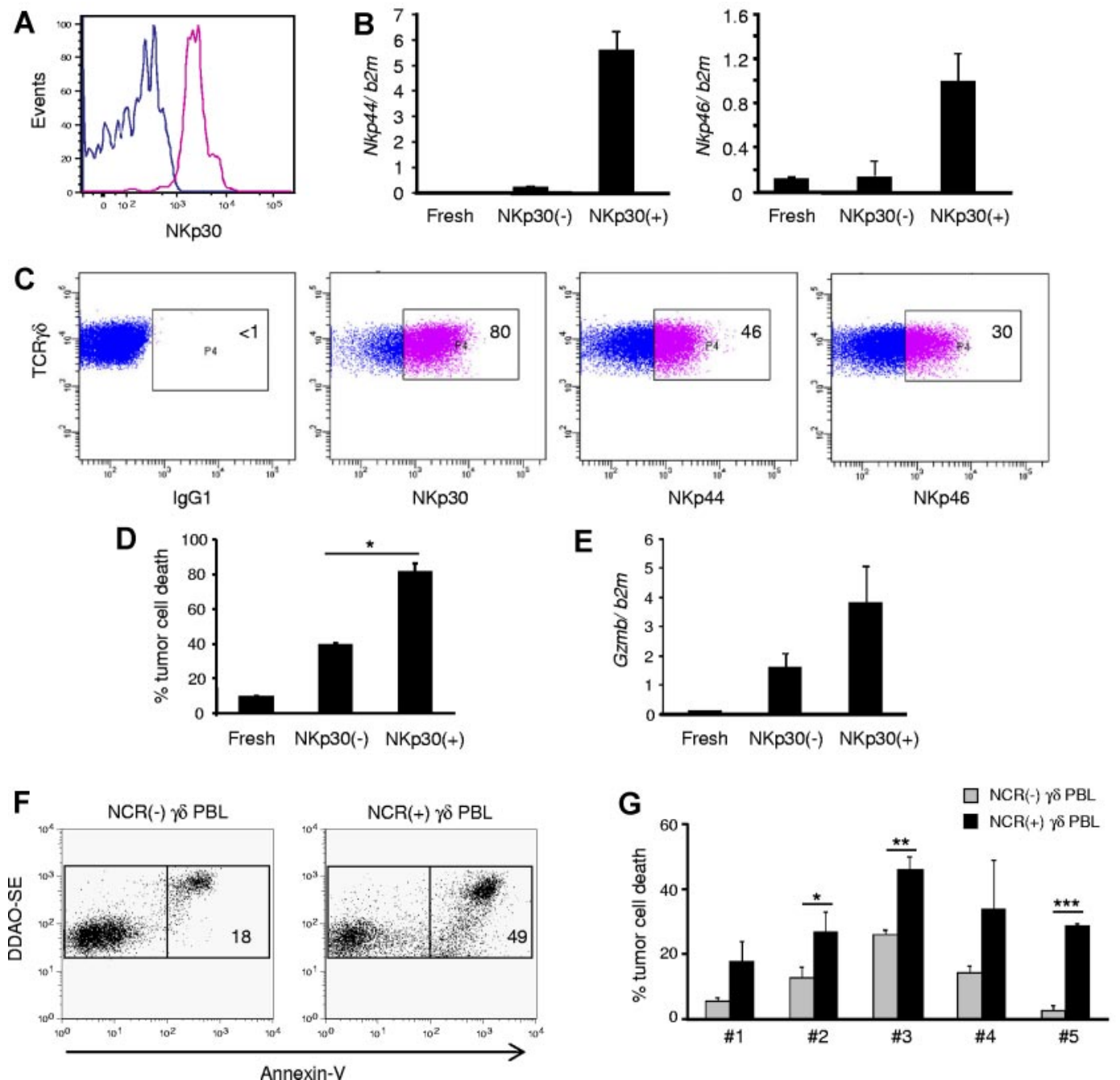

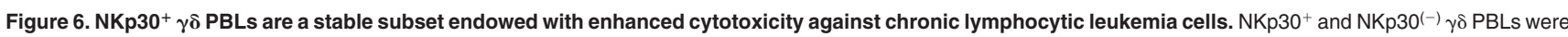
FACS-sorted from 14-day PHA and IL-2-activated cultures. (A) Reanalysis of NKp30 expression in the purified populations. (B) Real-time PCR quantification of Nkp44 (left) and $N k p 46$ (right) mRNA levels in NKp30- or NKp30 ${ }^{+} \gamma \delta$ T cells, compared with freshly isolated $\gamma \delta$ PBLs. Error bars represent SD ( $\mathrm{n}=3$ ). (C) Sorted NKp30 $\gamma \delta$ PBLs were cultured in the presence of IL-2. Analysis of NKp30, NKp44 and NKp46 expression after 14 days. (D) NKp30- or NKp30 ${ }^{+} \gamma \delta$ T cells, or freshly isolated $\gamma \delta$ PBLs, were used in killing assays with the leukemia cell line Bv173 (as in Figure 1). Tumor cell death was evaluated by annexin-V staining (n=3, $\left.{ }^{*} P<.05\right)$. (E) Real-time PCR quantification of GzmB mRNA levels in freshly isolated, NKp30(-) or NKp30 ${ }^{+} \gamma \delta$ T cells. Error bars represent SD $(n=3)$. (F-G) Representative plots $(F)$ and data summary $(\mathrm{G})$ for 5 primary B-cell chronic lymphocytic leukemia samples that were used in killing assays (as in Figure 1) with $\gamma \delta$ PBLs obtained from 6 distinct donors and activated with either HMB-PP and IL-2 or PHA and IL-2. NCR(-) $\gamma \delta$ PBL from HMB-PP and IL-2-activated cultures (gray bars) were compared with NCR(+) $\gamma \delta$ PBL from PHA and IL-2-activated cultures (black bars). Error bars represent $\operatorname{SD}\left(\mathrm{n}=6,{ }^{\star} P<.05 ;{ }^{* \star} P<.01 ;{ }^{\star \star \star} P<.001\right)$

abundance of $\mathrm{V} \delta 1^{+} \mathrm{T}$ cells at mucosal surfaces has been attributed to IL-15, which induces chromatin modifications that control TCR gene rearrangement. ${ }^{46}$

Our key demonstration that $\mathrm{NKp} 30^{+} \mathrm{V} \delta 1^{+}$cells are capable of targeting primary lymphoid leukemic cells is particularly relevant when taking into account that $\mathrm{V} \delta 1^{+} \mathrm{T}$ cells have been previously reported to be inefficient killers of primary leukemia or lymphoma cells ${ }^{44,45}$ which has been attributed to their lack of expression of NKG2D ligands. ${ }^{44}$ Interestingly, a recent study in which $\gamma \delta$ PBLs were activated with concanavalin A demonstrated higher killing ability of expanded $\mathrm{V} \delta 1^{+}$cells against B-CLL-derived cell lines. ${ }^{47}$ It will be important to investigate whether this protocol also induces $\mathrm{NKp} 30$ expression on $\mathrm{V} \delta 1^{+}$cells. Thus, $\mathrm{NKp} 30^{+} \mathrm{V} \delta 1^{+}$ cells may provide a valuable layer of intervention against lymphoid malignancies.

A surprising finding that deserves further investigation is the preferential expansion of $\mathrm{V} \delta 1^{+} \mathrm{T}$ cells (among $\gamma \delta \mathrm{PBL}$ ) on PHA treatment in vitro (Figure $3 \mathrm{~B}$ ). Because this is not due to selective apoptosis of the dominant $\mathrm{V} \delta 2^{+}$counterparts (supplemental Figure 2), it must derive from a proliferative advantage of $\mathrm{V} \delta 1^{+}$cells when receiving PHA-dependent TCR signals (Figure 3A-B). Provocatively, we have previously observed that $\mathrm{V} \delta 1^{+} \mathrm{T}$ cells express significantly higher levels of the CD27 receptor (compared with $\mathrm{V} \delta 2^{+}$cells) ${ }^{48}$; CD27 costimulation enhances Bcl2al and Cyclin D2 expression and promotes $\gamma \delta$ T-cell survival and proliferation. $^{48}$

This study draws important novel (NCR-mediated) insight into the modus operandis of human $\gamma \delta \mathrm{T}$ cells, and supports the emerging paradigm of $\gamma \delta$ T cells recognizing tumors via innate NK receptors rather than using the somatically rearranged TCR $\gamma \delta$ (Figure 5B-C). ${ }^{6}$ This notwithstanding, the TCR has a major, albeit indirect, contribution to the antitumor function of $\mathrm{NKp} 30^{+} \mathrm{V} \delta 1^{+}$ cells. We showed that efficient induction of NKp30 expression on $\mathrm{V} \delta 1^{+}$cells depends on TCR stimulation; in its absence, $\gamma_{c}$ cytokines can only effect a very modest up-regulation of NKp30 expression (Figure 4A-B). Thus, TCR signals are upstream of 
NKp30-mediated tumor cell recognition by NKp30+ V $81^{+}$lymphocytes. Interestingly, we have previously showed that, for $\mathrm{V} \delta 2^{+}$ cells, TCR signals are essential for cell activation and cytotoxic differentiation, "upstream" of tumor cell recognition via NKG2D. ${ }^{2}$ We therefore propose a "2-step" model for human $\gamma \delta \mathrm{T}$ cells, in which they differentiate and are activated like prototypic T cells (ie, using the TCR), but rely essentially on NK receptors (such as NKG2D, NKp30 or DNAM-1) for tumor cell recognition. This is consistent with the critical role described by the Hayday and Girardi groups for NKG2D ligands in tumor surveillance by mouse $\gamma \delta \mathrm{T}$ cells, ${ }^{49,50}$ and fits the general concept of NK receptors being the key molecular recognition determinants of "oncogenic stress."39

From a clinical perspective, this study describes a protocol to induce NKp30 ex vivo, which should make it very feasible to expand and inject large numbers of cells into patients. Importantly, we were able to efficiently expand $\mathrm{NKp} 30^{+} \mathrm{V} \delta 1^{+}$cells from B-CLL patients (supplemental Figure 10). On reinfusion, the activation status of the cells could potentially be maintained via administration of low doses of IL-2, which appears to be sufficient to sustain NKp30 expression. Thus, after this first

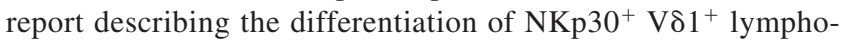
cytes, future work should evaluate their potential for adoptive cell immunotherapy of human cancer.

\section{Acknowledgments}

The authors thank Telma Lança, Haakan Norell, and Margareta Correia for suggestions; Alessandro Moretta and João T. Barata for materials; and the Serviço de Hematologia of Instituto Português de Oncologia de Lisboa for provision of leukemia samples.

This work was supported by the Young Investigator Program of the European Molecular Biology Organization and Fundação Calouste Gulbenkian SDH Oncologia 2008/99293 (B.S.-S.); and by the Italian Ministry of Health (Ricerca Finalizzata, ICH-2007643769), the European Union (Marie Curie International Reintegration Grant, 204188), and Istituto Clinico Humanitas (Intramural Research Program 20090917; D.M.). B.S.-S. is also funded by the European Research Council (StG260352), and D.V.C. is a $\mathrm{PhD}$ fellow of Fundação para a Ciência e Tecnologia (SFRH/BD/37898/2007).

\section{Authorship}

Contribution: D.V.C., M.F., and K.H. performed the experiments and analyzed the data; M.G.S. provided vital materials and technical help; D.M. and B.S.-S. designed the study and analyzed the data; and B.S.-S. wrote the manuscript.

Conflict-of-interest disclosure: The authors declare no competing financial interests.

The current affiliation for M.F. is the Department of Experimental and Applied Medicine, University of Brescia, Brescia, Italy.

Correspondence: Bruno Silva-Santos, Unidade de Imunologia Molecular, Instituto de Medicina Molecular, Avenida Prof Egas Moniz, 1649-028 Lisboa, Portugal; e-mail: bssantos@fm.ul.pt.

\section{References}

1. Vesely MD, Kershaw MH, Schreiber RD, Smyth MJ. Natural innate and adaptive immunity to cancer. Annu Rev Immunol. 2011;29:235-71.

2. Lança T, Correia DV, Moita CF, et al. The MHC class Ib protein ULBP1 is a nonredundant determinant of leukemia/lymphoma susceptibility to gammadelta T-cell cytotoxicity. Blood. 2010 115(12):2407-2411.

3. Gomes AQ, Correia DV, Grosso AR, et al. Identification of a panel of ten cell surface protein antigens associated with immunotargeting of leukemias and lymphomas by peripheral blood gammadelta $T$ cells. Haematologica. 2010;95(8):1397-1404.

4. Wilhelm M, Kunzmann V, Eckstein S, et al. Gammadelta T cells for immune therapy of patients with lymphoid malignancies. Blood. 2003;102(1) 200-206.

5. Dieli F, Vermijlen D, Fulfaro F, et al. Targeting human gammadelta $T$ cells with zoledronate and interleukin-2 for immunotherapy of hormone-refractory prostate cancer. Cancer Res. 2007; 67(15):7450-7457

6. Gomes AQ, Martins DS, Silva-Santos B. Targeting gammadelta $T$ lymphocytes for cancer immunotherapy: from novel mechanistic insight to clinical application. Cancer Res. 2010;70(24):1002410027.

7. Maeurer MJ, Martin D, Walter W, et al. Human intestinal Vdelta1 + lymphocytes recognize tumor cells of epithelial origin. J Exp Med. 1996;183(4): 1681-1696.

8. Choudhary A, Davodeau F, Moreau A, Peyrat MA, Bonneville M, Jotereau F. Selective lysis of autologous tumor cells by recurrent gammadelta tumor-infiltrating lymphocytes from renal carcinoma. J Immunol. 1995;154(8):3932-3940.

9. Groh V, Steinle A, Bauer S, Spies T. Recognition of stress-induced MHC molecules by intestinal epithelial gammadelta T cells. Science. 1998; 279(5357):1737-1740.
10. Groh V, Rhinehart R, Secrist H, Bauer S, Grabstein KH, Spies T. Broad tumor-associated expression and recognition by tumor-derived gammadelta T cells of MICA and MICB. Proc Natl Acad Sci U S A. 1999;96(12):6879-6884.

11. Greaves M, Janossy G, Doenhoff M. Selective triggering of human $T$ and $B$ lymphocytes in vitro by polyclonal mitogens. J Exp Med. 1974;140(1): 1-18.

12. Chen Y, Shao L, Ali Z, Cai J, Chen ZW. NSOM/ QD-based nanoscale immunofluorescence imaging of antigen-specific T-cell receptor responses during an in vivo clonal Vgamma2Vdelta2 T-cell expansion. Blood. 2008;111(8):4220-4232.

13. Correia DV, d'Orey F, Cardoso BA, et al. Highly active microbial phosphoantigen induces rapid yet sustained MEK/Erk- and PI-3K/Akt-mediated signal transduction in antitumor human gammadelta T cells. PLoS ONE. 2009;4(5):e5657.

14. Gomes AQ, Correia DV, Silva-Santos B. Nonclassical major histocompatibility complex proteins as determinants of tumour immunosurveillance. EMBO Rep. 2007;8(11):1024-1030.

15. Nedellec S, Sabourin C, Bonneville M, Scotet E. NKG2D costimulates human Vgamma9Vdelta2 $T$ cell antitumor cytotoxicity through protein kinase $\mathrm{C}$ theta-dependent modulation of early TCR-induced calcium and transduction signals. J Immunol. 2010;185(1):55-63.

16. Carlsten M, Bjorkstrom NK, Norell $\mathrm{H}$, et al. DNAX accessory molecule-1 mediated recognition of freshly isolated ovarian carcinoma by resting natural killer cells. Cancer Res. 2007;67(3):13171325.

17. Toutirais $\mathrm{O}$, Cabillic F, Le Friec G, et al. DNAX accessory molecule-1 (CD226) promotes human hepatocellular carcinoma cell lysis by Vgamma9Vdelta2 T cells. Eur J Immunol. 2009;39(5):1361-1368.

18. Lee KM, Forman JP, McNerney ME, et al. Requirement of homotypic NK-cell interactions through 2B4(CD244)/CD48 in the generation of NK effector functions. Blood. 2006;107(8):31813188.

19. Pende D, Parolini S, Pessino A, et al. Identification and molecular characterization of NKp30, a novel triggering receptor involved in natural cytotoxicity mediated by human natural killer cells. J Exp Med. 1999;190(10):1505-1516.

20. Behr C, Couzi L, Taupin J, Déchanet-Merville J. Vdelta2neg gammadelta T cells, a multi-reactive tissue subset: from innate to adaptive altered-self surveillance. Open Immunol. 2009;2:106-118.

21. Casetti R, Perretta G, Taglioni A, et al. Drug-induced expansion and differentiation of Vgamma9Vdelta2 T cells in vivo: the role of exogenous IL-2. J Immunol. 2005;175(3):1593-1598.

22. Chilson OP, Kelly-Chilson AE. Mitogenic lectins bind to the antigen receptor on human lymphocytes. Eur J Immunol. 1989;19(2):389-396.

23. Cantrell D. Protein kinase B (Akt) regulation and function in T lymphocytes. Semin Immunol. 2002; 14(1):19-26.

24. Alexander AA, Maniar A, Cummings JS, et al. Isopentenyl pyrophosphate-activated CD56+ gammadelta T lymphocytes display potent antitumor activity toward human squamous cell carcinoma. Clin Cancer Res. 2008;14(13):4232-4240.

25. Sivori S, Vitale M, Morelli L, et al. p46, a novel natural killer cell-specific surface molecule that mediates cell activation. J Exp Med. 1997;186(7): 1129-1136.

26. Pessino A, Sivori S, Bottino C, et al. Molecular cloning of NKp46: a novel member of the immunoglobulin superfamily involved in triggering of natural cytotoxicity. J Exp Med. 1998;188(5):953960.

27. Vitale M, Bottino C, Sivori S, et al. NKp44, a novel triggering surface molecule specifically expressed by activated natural killer cells, is involved in non-major 
From bloodjournal.hematologylibrary.org at IRCCS ISTITUTO CLINICO HUMANITAS on August 2, 2011. For

histocompatibility complex-restricted tumor cell lysis. J Exp Med. 1998;187(12):2065-2072.

28. Correia MP, Cardoso EM, Pereira CF, Neves R, Uhrberg M, Arosa FA. Hepatocytes and IL-15: a favorable microenvironment for $T$ cell survival and CD8+ T cell differentiation. J Immunol. 2009; 182(10):6149-6159.

29. Tang Q, Grzywacz B, Wang H, et al. Umbilical cord blood T cells express multiple natural cytotoxicity receptors after IL-15 stimulation, but only NKp30 is functional. J Immunol. 2008;181(7): 4507-4515.

30. Arnon TI, Achdout H, Levi O, et al. Inhibition of the NKp30 activating receptor by pp 65 of human cytomegalovirus. Nat Immunol. 2005;6(5):515523.

31. Hershkovitz O, Rosental B, Rosenberg LA, et al. NKp44 receptor mediates interaction of the envelope glycoproteins from the West Nile and dengue viruses with NK cells. J Immunol. 2009; 183(4):2610-2621.

32. Carbone E, Neri P, Mesuraca M, et al. HLA class I, NKG2D, and natural cytotoxicity receptors regulate multiple myeloma cell recognition by natural killer cells. Blood. 2005;105(1):251-258.

33. Lakshmikanth T, Burke S, Ali TH, et al. NCRs and DNAM-1 mediate NK cell recognition and lysis of human and mouse melanoma cell lines in vitro and in vivo. J Clin Invest. 2009;119(5):1251-1263.

34. Fauriat C, Just-Landi S, Mallet F, et al. Deficient expression of NCR in NK cells from acute myeloid leukemia: Evolution during leukemia treatment and impact of leukemia cells in NCRdull phenotype induction. Blood. 2007;109(1):323330.
35. Hollyoake M, Campbell RD, Aguado B. NKp30 (NCR3) is a pseudogene in 12 inbred and wild mouse strains, but an expressed gene in Mus caroli. Mol Biol Evol. 2005;22(8):1661-1672.

36. Arnon TI, Lev M, Katz G, Chernobrov Y, Porgador A, Mandelboim O. Recognition of viral hemagglutinins by NKp44 but not by NKp30. Eur J Immunol. 2001;31(9):2680-2689.

37. Mandelboim O, Lieberman N, Lev M, et al. Recognition of haemagglutinins on virus-infected cells by NKp46 activates lysis by human NK cells. Nature. 2001;409(6823):1055-1060.

38. Brandt CS, Baratin M, Yi EC, et al. The B7 family member $\mathrm{B} 7-\mathrm{H} 6$ is a tumor cell ligand for the activating natural killer cell receptor NKp30 in humans. J Exp Med. 2009;206(7):1495-1503.

39. Raulet DH, Guerra N. Oncogenic stress sensed by the immune system: role of natural killer cell receptors. Nat Rev Immunol. 2009;9(8):568-580.

40. De Rosa SC, Andrus JP, Perfetto SP, et al. Ontogeny of gamma delta T cells in humans. $\mathrm{J} / \mathrm{m}$ munol. 2004;172(3):1637-1645.

41. Vermijlen D, Brouwer M, Donner C, et al. Human cytomegalovirus elicits fetal gammadelta T cell responses in utero. J Exp Med. 2010;207(4):807821.

42. Déchanet J, Merville P, Lim A, et al. Implication of gammadelta $T$ cells in the human immune response to cytomegalovirus. J Clin Invest. 1999; 103(10):1437-1449.

43. Boullier S, Cochet M, Poccia F, Gougeon ML CDR3-independent gamma delta $V$ delta $1+$ $\mathrm{T}$ cell expansion in the peripheral blood of HIVinfected persons. J Immunol. 1995;154(3):14181431.
44. Poggi A, Venturino C, Catellani S, et al. Vdelta1 T lymphocytes from B-CLL patients recognize ULBP3 expressed on leukemic B cells and upregulated by trans-retinoic acid. Cancer Res. 2004;64(24):9172-9179.

45. Catellani S, Poggi A, Bruzzone A, et al. Expansion of Vdelta1 T lymphocytes producing IL-4 in low-grade non-Hodgkin lymphomas expressing UL-16-binding proteins. Blood. 2007;109(5): 2078-2085.

46. Zhao H, Nguyen $\mathrm{H}$, Kang J. Interleukin 15 controls the generation of the restricted T cell receptor repertoire of gamma delta intestinal intraepithelial lymphocytes. Nat Immunol. 2005;6(12): 1263-1271.

47. Siegers $\mathrm{GM}$, Dhamko $\mathrm{H}$, Wang $\mathrm{XH}$, et al. Human Vdelta1 gammadelta $T$ cells expanded from peripheral blood exhibit specific cytotoxicity against B-cell chronic lymphocytic leukemia-derived cells Cytotherapy. 2011;13:753-764.

48. DeBarros A, Chaves-Ferreira M, d'Orey F, Ribot JC, Silva-Santos B. CD70-CD27 interactions provide survival and proliferative signals that regulate T cell receptor-driven activation of human gammadelta peripheral blood lymphocytes. Eur J Immunol. 2011;41(1):195-201.

49. Girardi M, Oppenheim DE, Steele CR, et al. Regulation of cutaneous malignancy by gammadelta T cells. Science. 2001;294(5542):605-609.

50. Strid J, Roberts SJ, Filler RB, et al. Acute upregulation of an NKG2D ligand promotes rapid reorganization of a local immune compartment with pleiotropic effects on carcinogenesis. Nat Immunol. 2008;9(2):146-154. 